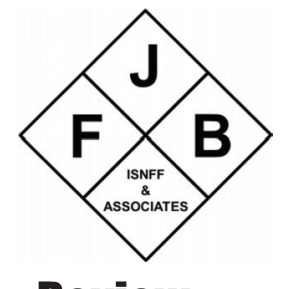

Journal of

Food Bioactives

International Society for

Nutraceuticals and Functional Foods

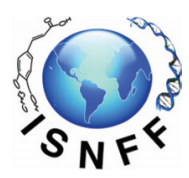

Review

J. Food Bioact. 2021;14:10-19

\title{
Are omega-3 fatty acids efficacious in the treatment of depression? A review
}

\author{
Klaus W. Lange ${ }^{\mathrm{a}^{*}}$, Yukiko Nakamura ${ }^{\mathrm{a}}$, Hui Zhao ${ }^{\mathrm{b}}$, Disi Baic and Haitao Wang ${ }^{\mathrm{c}}$

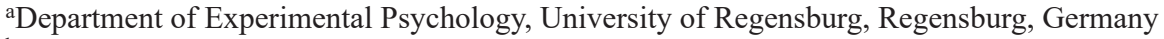 \\ ${ }^{\mathrm{b}}$ Tianjin Key Laboratory of Food and Biotechnology, Tianjin University of Commerce, Tianjin, China \\ 'School of Psychology and Mental Health, North China University of Science and Technology, Tangshan, China \\ *Corresponding author: Klaus W. Lange, Institute of Psychology, University of Regensburg, 93040 Regensburg, Germany. Tel: +49 941 \\ 9433815; Fax: +49 941 9434496; E-mail: klaus.lange@ur.de \\ DOI: $10.31665 / J F B .2021 .14265$
}

Received: June 17, 2021; Revised received \& accepted: June 29, 2021

Citation: Lange, K.W., Nakamura, Y., Zhao, H., Bai, D., and Wang, H. (2021). Are omega-3 fatty acids efficacious in the treatment of depression? A review. J. Food Bioact. 14: 10-19.

\begin{abstract}
The hypothesis that omega- 3 fatty acids may play a role in preventing and treating depression is based on correlative associations between fish consumption, omega-3 fatty acid intake and the prevalence of major depressive disorder. Reduced omega-3 fatty acid erythrocyte levels have been found in individuals with depressive disorders. These observational findings are unable to establish a causal relationship between omega- 3 fatty acids and depression. The results of randomized controlled trials of omega-3 fatty acids for depressive disorders are inconclusive and also fail to prove causation. The therapeutic efficacy of omega-3 fatty acids appears to be moderate at best but is more likely to be minimal or non-existent. Potential long-term adverse effects of omega-3 fatty acid supplementation should be considered. Large-scale, well-controlled clinical trials are required to establish potential anti-depressive effects of omega- 3 fatty acids. Such studies need to consider baseline values of omega-3 fatty acids and symptom severity, the dosage and types of the fatty acids used, the duration of supplementation and the concomitant use of medication. Conclusive evidence of the efficacy of omega-3 fatty acids in depression is currently lacking. The recommendation of potentially ineffective therapies may have considerable opportunity costs, with other possibly more useful treatments remaining unutilized.
\end{abstract}

Keywords: Omega-3 fatty acids; Depression; Treatment; Adverse effects; Opportunity cost.

\section{Introduction}

Depression is highly prevalent worldwide and is common across the entire lifespan (Kessler et al., 2007). Major depressive disorder is predicted to become the leading cause of burden of disease globally by 2030 (Kessler et al., 2003; World Health Organization, 2008). The 12-month prevalence of major depressive disorder has been found to be $6.6 \%$, and the lifetime prevalence is $16.2 \%$ (Kessler et al., 2007). The disorder is highly debilitating, causing considerable functional disability and reduced quality of life, with severe limitation of psychosocial functioning in affected people (Malhi and Mann, 2018).
Depression, with its high rate of recurrence, is difficult to treat (Malhi and Mann, 2018), and despite recent advances, the treatments available for major depressive disorder remain less than satisfactory. Pharmacological therapy and manual-based psychotherapy, mainly cognitive behavioral therapy, have been shown to be effective in the treatment of depression, either administered alone or in combination (Cuijpers et al., 2008; Cuijpers et al., 2009). However, a degree of non-response to pharmacotherapy has been estimated to pose a challenge in up to $60 \%$ of people with major depressive disorder (Fava, 2003). The switching of antidepressant medications is a commonly used approach in the therapy of depression, although the effectiveness of this strategy in ameliorating 
symptoms is controversial (Bschor and Baethge, 2010). Approximately $30 \%$ of individuals treated for depression remain refractory to multistep antidepressant therapies (Rush et al., 2006a; Rush et al., 2006b). Furthermore, the long-term effectiveness of pharmacotherapy and psychotherapy and their capacity to avert disease burden remains a matter of debate (Casacalenda et al., 2002). The need for the development of further medications for the treatment of depression has repeatedly been emphasized (Insel, 2015; Miller, 2010), as has the need for novel approaches to the prevention and therapy of depression.

Nutrition and diet quality have been shown not only to play an important role in the promotion of metabolic health (Bennett et al., 2015), but also to be involved in mental health and to be factors able to modify mental disorders (Lange, 2018, 2020a, 2020b; Marx et al., 2017). For example, the risk of depression has been reported to be inversely associated with the Mediterranean diet, which comprises limited quantities of processed foods and large amounts of vegetables, fruit, nuts, seeds, wholegrains and fish (Lai et al., 2014; Opie et al., 2015; Psaltopoulou et al., 2013). In contrast, Western diets with their high content of high-sugar, high-fat and processed foods have been found to be positively correlated with depression (Lai et al., 2014). Several systematic reviews and meta-analyses have confirmed the association between diet, nutrition and depression in adults (Lai et al., 2014; Psaltopoulou et al., 2013). Food bioactives, such as omega-3 polyunsaturated fatty acids, L-theanine, epigallocatechine gallate and probiotics, have also been associated with depression risk (Lange, 2020c; Lange et al., 2020; Lange et al., 2021). These findings have led to the investigation of nutritional supplementation as monotherapy or adjunctive therapy in depression (Lim et al., 2016).

\section{Rationale for the use of omega-3 fatty acids in depression}

The relevance of lipids in brain function is highlighted by the fact that, with the exception of adipose tissue, the brain contains the highest lipid concentration in the body of mammals, with lipids accounting for $50-60 \%$ of the brain's dry weight (Sastry, 1985).

Omega-3 fatty acids exert both long-term and short-term actions in the central nervous system. Their long-term effects include an influence on the production, maintenance and function of brain structures. The short-term effects of omega- 3 fatty acids concern the physiology of neuronal signal transduction (Bazinet and Layé, 2014). In particular, docosahexaenoic acid (DHA) and eicosapentaenoic acid (EPA) have been linked to the maintenance of mental health. Dietary deficiencies of these fatty acids have been implicated in the pathophysiology and increased risk of a range of mental disorders, including unipolar depression, bipolar disorder, schizophrenia, dementia, autism and attention-deficit/hyperactivity disorder (Lange, 2020a, 2020b). The findings of animal experiments suggest that omega- 3 fatty acids may affect several of the neurobiological mediators believed to be involved in the pathophysiology of major depressive disorder (Müller et al., 2015). Lipids are involved in the function of neuronal membranes as a barrier and a medium for neurotransmitter signaling. Changes in membrane lipids might contribute to the pathophysiology of depression and could therefore become targets of lipid-based treatments (Müller et al., 2015).

The rationale underlying the emerging concept of the use of omega-3 fatty acids in preventing and treating depression (Ross, 2016) is premised on several lines of observational evidence, including a correlational relationship between the consumption of fish and a low prevalence of major depressive disorder. An often cited study in this context reported that a low annual intake of fish was associated with a relatively high rate of major depression in countries such as Canada, France, Germany and New Zealand, while high fish intake in Japan, Korea and Taiwan was associated with a particularly low prevalence of depression (Hibbeln, 1998). These findings are commonly interpreted as suggestive of preventive effects of fish consumption on depression. However, the report cautioned against overhasty conclusions. It stated explicitly that fish consumption has not been demonstrated to cause differences in the prevalence of depression and that a range of influences, such as economic, social, cultural and other unknown factors, may be confounders of this simple correlational relationship (Hibbeln, 1998)

A systematic review and meta-analysis of findings conducted on the basis of 31 observational studies (with a total of 255,076 participants and more than 20,000 people with depression) evaluated the association between depression, fish consumption and dietary omega-3 fatty acid intake (Grosso et al., 2016). The analysis found a significantly reduced risk of depression associated with fish consumption, with a linear dose-response (Grosso et al., 2016). Another systematic review and meta-analysis of the findings of 10 prospective cohort studies (comprising a total of 109,764 participants and 6,672 people with depression) reported a modest inverse association between fish consumption or omega-3 fatty acid intake and the risk of depression, especially in females (Yang et al., 2018). The correlation found between fish consumption and major depression accords with clinical findings demonstrating that higher DHA levels in erythrocyte membranes (Edwards et al., 1998a) and higher plasma ratios of EPA to arachidonic acid (Adams et al., 1996) predict less severe symptoms of depression. As indicated above, these findings do not necessarily imply a causal relationship between fish consumption and the prevalence of major depression, or point to a therapeutic effect of the intake of fish or fish oil supplements in the therapy of depression. Inverse associations between omega- 3 fatty acid intake and depressive symptoms have also been demonstrated in other studies (Silvers and Scott, 2002; Tanskanen et al., 2001). Furthermore, lower omega-3 fatty acid levels have been found in people diagnosed with major depressive disorder in comparison with controls (Edwards et al., 1998b; Peet et al., 1998). Continuous relationships between omega-3 fatty acid status and symptoms of depression have also been observed (Edwards et al., 1998b). In addition, individuals diagnosed with depression have been shown to have significantly reduced omega-3 fatty acid levels and an elevated ratio of omegy- 6 to omega- 3 polyunsaturated fatty acid levels in both blood and brain (McNamara and Liu, 2011; Parletta et al., 2016).

In contrast, a number of cross-sectional studies showed either no associations between depressive symptoms and the intake of omega-3 fatty acids (Hakkarainen et al., 2004; Miyake et al., 2006), or some associations, which were explained entirely by confounding variables (Appleton et al., 2007). Several other studies also failed to establish relationships between omega- 3 fatty acid concentrations and symptoms of depression (Appleton et al., 2008; Browne et al., 2006; Mamalakis et al., 2004)

In summary, the observational or epidemiological evidence regarding the role of omega-3 fatty acids in major depressive disorder is ambiguous. Moreover, the observational studies suggesting a link between depression and omega-3 fatty acids may be subject to confounding and selection bias, since unmeasured or unmeasurable factors may have affected the associations found (Sackett, 1979). The health effects of foods, as suggested by epidemiological studies, may be influenced by numerous other known or unknown lifestyle factors. For example, elderly people in France consuming fish regularly (at least weekly) showed fewer depressive symptoms 
and higher scores in the Mini Mental Status Examination than people in a control group; however, the experimental group was also better educated and higher earning (Barberger-Gateau et al., 2005). Thus, observational studies cannot establish causal relationships between intervention and outcome. Randomized controlled trials are needed to elucidate causality.

\section{Animal studies}

Animal studies have provided consistent evidence supporting a link between reduced brain levels of DHA and altered performance in behavioral and cognitive tasks (Hauser et al., 2018; Lange et al., 2018; Lange, 2020c; Ruhland et al., 2020). In particular, preclinical experiments have demonstrated that a diet deficient in omega-3 fatty acids induces depressive-like and abnormal social behavior in rodents (Bondi et al., 2014; Lafourcade et al., 2011; Larrieu et al., 2014; Larrieu et al., 2016). For example, mice reared on an omega-3 fatty acid-deficient diet had reduced concentrations of polyunsaturated fatty acids such as DHA and increased levels of omega- 6 fatty acids in the brain and displayed a range of depressive symptoms in behavioral tests. The deficient animals were less inclined to explore and gave up more easily in a forced swimming task (Lafourcade et al., 2011). Rats subjected to an omega-3 fatty acid deficiency in the 15 weeks following weaning were found to exhibit higher depression-like symptoms in a forced swimming test (DeMar et al., 2006). Studies in rat models have also shown that omega- 3 fatty acids could prevent and reduce depression-like behaviors (Carlezon et al., 2005; Huang et al., 2008; Lakhwani et al., 2007; Song et al., 2009). Further investigations are needed to determine whether dietary omega-3 fatty acid deficiency is responsible for depression-like behaviors in rodents (Krishnan and Nestler, 2008).

The findings of animal studies have also provided clues as to the biological mechanisms mediating the effects of omega- 3 fatty acids. DHA appears to act on the brain through a direct effect on free fatty acid receptors or other indirect mechanisms. Indirect mechanisms relevant to the modulation of mood-related behaviors include effects of omega-3 fatty acids on the endocannabinoid system, the hypothalamic-pituitary-adrenal axis, neuroinflammatory pathways and neuronal plasticity in the hippocampus (Larrieu and Layé, 2018). However, it should be borne in mind that the commonly used animal models of major depressive disorder have substantial shortcomings, particularly in regard to depression subtypes, therapy-resistant depression and recurrent depression (Planchez et al., 2019).

\section{Clinical trials}

A number of randomized controlled trials have shown beneficial effects of omega-3 fatty acid administration compared to placebo in both major depressive disorder (Nemets et al., 2002; Su et al., 2003) and other depressive conditions (Frangou et al., 2006; Stoll et al., 1999). Several other randomized controlled trials observed no benefit of omega-3 fatty acid supplementation in people with major depressive disorder (Grenyer et al., 2007; Silvers et al., 2005) or other depressive disorders (Keck et al., 2006; Rogers et al., 2008) when compared with placebo.

Systematic reviews and meta-analyses have found significant variability between studies (Appleton et al., 2006; Appleton et al., 2008; Appleton et al., 2010; Lin and Su, 2007). Some meta-analyses showed positive effects of omega- 3 fatty acids for depres- sive disorders (Appleton et al., 2010; Lin and Su, 2007), but these effects were dependent on the severity of depressive symptoms at baseline (Appleton et al., 2010), with people suffering severe depressive symptoms showing some positive effects, while no benefits were reported in individuals with mild symptoms (Appleton et al., 2010). A Cochrane review summarized the results of randomized controlled trials examining the effects of omega-3 fatty acids on major depressive disorder in adults (Appleton et al., 2016). Twenty-five trials (with a total of 1,373 participants) investigating omega-3 fatty acid effects versus placebo showed smallto-moderate benefits for depressive symptoms (Appleton et al., 2016). However, the quality of evidence provided was considered very low and biased, and the effects were judged to be without clinical relevance (Appleton et al., 2016). The Cochrane review concluded that the available evidence was insufficient to allow a determination on whether or not omega-3 fatty acids are effective in the therapy of major depressive disorder. One study included in this review, with a small sample of 40 participants, found no differences between omega- 3 fatty acids and antidepressant medications in regard to depressive symptomatology or rates of response to treatment (Jazayeri et al., 2008). A more recent meta-analysis of 26 double-blind randomized placebo-controlled trials including 2,160 participants found an overall beneficial effect of omega-3 fatty acids on depressive symptoms (Liao et al., 2019). However, the effect sizes were small to modest, and substantial evidence of heterogeneity between studies was detected (Liao et al., 2019).

A further meta-analysis addressed several shortcomings of other analyses. It included only studies with depression as the primary indication and adjusted for publication bias using the trim-andfill method (Bloch and Hannestad, 2012). This study found that omega-3 fatty acid supplementation produced small and insignificant effects on depression, with significant heterogeneity between studies. Following correction for publication bias, most effects of omega-3 fatty acids were eradicated and the results became insignificant. Greater efficacy of omega-3 fatty acids was associated with higher depression severity at baseline as well as shorter duration and lower quality of trials (Bloch and Hannestad, 2012). Another important methodological issue was the insufficient blinding (due to the fishy aftertaste of the preparations used) of early studies assessing the effects of omega-3 fatty acids (Sontrop and Campbell, 2006). These lower-quality studies may have increased the effect sizes of their results rather than the efficacy of omega- 3 supplementation.

DHA and EPA may have different effects in depression as a result of their different roles in anti-inflammatory activity and in the maintenance of the fluidity and integrity of membranes (Deacon et al., 2017). The therapeutic efficacy of omega-3 fatty acid supplementation may therefore be influenced by the dosage and proportion of EPA and DHA. Several meta-analyses have addressed the issue of possible differences between different types of omega-3 fatty acids. In these studies, omega-3 fatty acid supplementation using formulations containing mainly EPA were found to show significantly greater efficacy than those with higher DHA content (Grosso et al., 2014; Hallahan et al., 2016; Liao et al., 2019; Sublette et al., 2011).

A review of a total of 40 studies, including 31 randomized placebo-controlled trials, observed the effects of omega-3 fatty acids as add-on to antidepressant pharmacotherapy in major depressive disorder or ongoing depression (Sarris et al., 2016). The review found that adjunctive administration of omega- 3 fatty acids decreased symptoms of depression compared to placebo (Sarris et al., 2016).

Postpartum depression is a major mood disorder (Mann et al., 2010) whose risk seems to be associated with neuroinflammation 
(Simpson et al., 2016) and decreased serotonergic neurotransmission (Jans et al., 2007). Risk factors of postpartum depression include inadequate intake or depletion of food bioactives, including omega-3 fatty acids, during pregnancy and lactation (Golding et al., 2009; Rees et al., 2009; Sontrop et al., 2008). A review of available studies found that supplementation of EPA-rich oil decreased some of the symptoms of depression during pregnancy and following childbirth (Hsu et al., 2018). Long-term supplementation of DHA-rich oils was shown to reduce the risk of postpartum depression in healthy pregnant women, but not in lactating women (Hsu et al., 2018).

Several studies have examined the effects of omega-3 fatty acids on depressed mood in elderly people. A systematic review including nine studies assessing the efficacy of the administration of omega- 3 polyunsaturated fatty acids in individuals aged 60 years or older reported no significant overall effects in improving depressive symptoms (Bai et al., 2018). However, trials using omega-3 fatty acid dosages greater than $1.5 \mathrm{~g}$ /day showed a statistically significant symptom reduction (Bai et al., 2018). A systematic review and meta-analysis including six randomized controlled trials comprising 4,605 participants indicated no significant effects of omega-3 fatty acid administration on depressed mood in elderly people with good mental health, while a large effect was revealed in older individuals with depression (Bae and Kim, 2018). However, beneficial effects were significant only for people with mildto-moderate depression (Bae and Kim, 2018).

In children and adolescents diagnosed with depression, the few randomized controlled trials on omega- 3 fatty acids that have been conducted included small sample sizes. In the largest study conducted, including 72 young people aged 7 to 14 years with depressive disorders, treatment with omega- 3 fatty acids for 12 weeks showed a small-to-medium effect in comparison with placebo control (Fristad et al., 2019). In contrast, no beneficial effects of a 10-week administration of omega-3 polyunsaturated fatty acids were observed in a randomized controlled trial comprising 51 adolescents with major depressive disorder (Gabbay et al., 2018). The evidence base for omega-3 fatty acid supplementation in pediatric depression is therefore insufficient.

In summary, the findings of the meta-analyses of randomized controlled trials of omega-3 fatty acids for depressive disorders are inconclusive. Major problems of the available trials include methodological shortcomings, different outcome measures and significant heterogeneity between the studies regarding sample populations, type of treatment (monotherapy or add-on therapy) as well as dosage, duration and ratio of EPA and DHA supplementation (Nasir and Bloch, 2019).

\section{Adverse effects of omega-3 fatty acid supplementation}

As food supplements, omega- 3 fatty acids are not required to conform to the criteria of efficacy and safety set by authorities controlling or regulating the use of medications. In view of the increasing interest in omega-3 fatty supplementation, the question of potential adverse effects must be addressed. Common side effects of omega-3 fatty acid administration using fish oil preparations include fishy belching, flatulence, diarrhea and mild nausea (Mehta, 2004; Sydenham et al., 2012). Some studies have reported that high doses of omega-3 fatty acids ( $>3$ g daily) may increase the risk of bleeding, prolong bleeding time or cause bleeding gums, epistaxis and even hemorrhagic stroke (Clarke et al., 1990; Clarke et al., 2005; Emsley et al., 2002; Emsley et al., 2006; McEwen et al., 2013; Pascoe et al., 2014). In general, good tolerability of omega-3 fatty acids can be assumed.

However, clinical trials reporting similar rates of side effects of omega-3 fatty acids in comparison with placebo were of short duration only. The prolonged administration of omega- 3 fatty acids at supra-physiological doses may be associated with late adverse effects, which elude detection during the trial duration (Lange et al., 2019). Potentially serious adverse events following the supplementation of other natural nutrients have been reported. For example, supplementation of vitamin $\mathrm{E}$ has shown a trend towards an increase in risk of prostate cancer (Klein et al., 2011), while selenium intake increased the risk of diabetes (Dunn et al., 2010).

Omega-3 polyunsaturated fatty acids are highly prone to oxidative degradation. Fish oil supplements therefore contain antioxidants as well as oxidation products of omega-3 fatty acids, both of which could be associated with adverse effects. Antioxidants added to fish oils can reduce but not completely prevent oxidation (Zuta et al., 2007). Concerns regarding the safety of oxidized fish oil were raised as early as the 1950s (Kaneda and Ishii, 1953; Matsuo, 1954). Animal studies have shown that oxidized lipid products can be harmful (Esterbauer, 1993). A substantial proportion of commercially available fish oil preparations have been reported to be oxidized (Fantoni et al., 1996; Fierens and Corthout, 2007; Halvorsen and Blomhoff, 2011; Kolanowski, 2010; Opperman and Benade, 2013), with total oxidation and levels of peroxide (reflecting primary oxidation) and anisidine (secondary oxidation product) significantly exceeding the internationally recommended values (Albert et al., 2015; Bannenberg et al., 2017; Jackowski et al., 2015). The omega-3 fatty acid supplements administered in clinical trials could therefore have been partially oxidized, possibly confounding the results of these studies. Furthermore, the potential of the supplements to cause harm in humans remains unknown, since "information on the level of oxidation of fish oil ..... and related toxicological effects in humans is lacking" (EFSA Panel on Biological Hazards, 2010). The effects of oxidized oils on human health therefore require investigation.

Vitamin E (tocopherols and tocotrienols) is the antioxidant commonly added to fish oil supplements. Possible adverse effects of the long-term administration of vitamin $\mathrm{E}$ should be considered, since large-scale trials of $\alpha$-tocopherol (dominant active ingredient of vitamin E) supplementation have suggested a link to increased rates of prostate carcinoma (Yang et al., 2012). In addition, the findings of a large prospective study suggest that DHA may increase the risk of high-grade prostate cancer (Brasky et al., 2011). An elevated risk of high-grade and low-grade prostate cancer in men with high blood levels of omega-3 fatty acids (EPA, DHA and eicosapentaenoic acid) was found in a large, prospective casecohort study (Brasky et al., 2013). A case-control study reported a slightly elevated prostate cancer risk in the highest compared to the lowest quintile of plasma EPA and DPA levels (Crowe et al., 2014). Furthermore, a recent systematic review and meta-analysis comprising 47 randomized controlled trials (with a total of 108,194 participants) found that the intake of omega- 3 fatty acids may slightly increase prostate cancer risk (Hanson et al., 2020). The findings above have shown an association between plasma phospholipid omega-3 fatty acids and risk of prostate carcinoma. While causation has not been demonstrated, the consistency of the findings suggests a potential role of omega-3 fatty acids in prostate tumorigenesis.

The mechanisms involved in a link between vitamin $\mathrm{E}$ and prostate cancer remain speculative. Genetic variation may determine the potential role of $\alpha$-tocopherol in carcinogenesis. The COMT gene encodes the production of catechol-O-methyltransferase, which is involved in the processing of vitamin E. Variations in the gene have been found to influence the effects of $\alpha$-tocopherol on 
cancer incidence (Hall et al., 2019). Furthermore, testosterone has been implicated in the etiology of prostate carcinoma (Taylor et al., 2010). Following supplementation with fish oil, young men have been shown to have larger testicle size and an elevated free testosterone to LH ratio in comparison with their unsupplemented counterparts (Jensen et al., 2020). A recent pooled prospective analysis suggests that low free testosterone levels are associated with a reduced risk of prostate cancer, suggesting that circulating free testosterone may play a role in cancer risk. Further research is required to assess whether this association is causal and to clarify the importance of high testosterone levels (Watts et al., 2018).

In summary, oil contained in omega-3 fatty acid supplements may also contain unspecified concentrations of potentially toxic oxidation products, the health consequences of which remain unclear. Harmful effects of oxidized lipid products have been found in preclinical studies. Caution is therefore needed when omega-3 polyunsaturated fatty acids are administered at high doses over extended periods of time, especially during prenatal development and childhood. Potential long-term adverse effects of vitamin $\mathrm{E}$ added as an antioxidant should also be considered.

\section{Future directions}

Epidemiological and other observational studies are unable to provide definitive evidence of the efficacy of omega- 3 fatty acids in depression, since potential confounding by lifestyle (e.g. dietary habits, physical activity, smoking and alcohol intake), socioeconomic and cultural factors cannot be excluded. Therefore, no conclusions regarding cause and effect can be drawn from cross-sectional studies. Prospective randomized controlled trials are needed to confirm a causal relation between omega-3 fatty acid intake and depressive symptoms (see Table 1).

While the available results of clinical trials have been interpreted as support for the potential of omega-3 fatty acids in the treatment of depression, several cautionary notes need to be considered. The trials included in the meta-analyses examining omega-3 fatty acids and depression vary markedly in regard to participants, diagnostic criteria, intervention type, dosage, duration, baseline omega-3 status and outcome measures. These variations may contribute substantially to the heterogeneity of studies, which limits the validity of the pooled results. The short trial duration of several weeks or months provides no information on the long-term effects of omega-3 fatty acid supplementation on depression. The sample sizes of many of the randomized controlled trials were small, potentially leading to an overestimation of treatment effects and publication bias (Nüesch et al., 2010; Sterne et al., 2000).

Various clinical factors need to be taken into account when investigating omega-3 fatty acids and depression. For example, in view of differences in diagnostic methods, the comparison of the available studies in humans is problematic. While many studies relied on self-reporting of participants, others used more reliable semi-structured assessment tools or a clinical diagnosis made by specialists. Many studies on depression are confined to either community samples or clinical/medical samples, and their respective findings may not be generalizable to entire populations. The age of the individuals included in such studies is also important. Furthermore, the respective effects of omega-3 fatty acids on depressive symptoms in individuals with mild, moderate and severe degrees of major depressive disorder should be considered. In addition, a variety of biological, social, environmental and cultural factors may be involved in the etiology of depression (Malhi and Mann, 2018). Depression is therefore likely to be a pathogenetically, physiologically and clinically heterogeneous condition. In consequence, not every individual with depression has an omega-3 deficiency, and the efficacy of omega-3 fatty acids may be confined to subgroups yet to be identified. Another consideration concerns the impact of depression on lifestyle. An improved lifestyle structure in the context of adherence to a clinical trial could have beneficial effects. Moreover, omega-3 fatty acid supplementation may produce positive effects on general wellbeing and health, since polyunsaturated fatty acids may be beneficial for cardiovascular health and metabolic problems (Carpentier et al., 2006; Sudheendran et al., 2010). In addition, many participants included in the omega-3 fatty acid trials may have had comorbid conditions, potentially affecting their response to supplementation.

The impact of different types of omega- 3 fatty acids on depressive symptoms requires further studies, since the omega- 3 fatty acid composition of the fish oils used differed between studies. EPA rather than DHA has been suggested to mediate the beneficial effects of omega-3 fatty acids in major depressive disorders (Grosso et al., 2014; Hallahan et al., 2016; Martins, 2009; Martins et al., 2012). Future trials could therefore focus on supplementation with EPA alone or a combination of omega-3 fatty acids with a predominance of EPA. Furthermore, the oxidative status of the fish oils used needs to be assessed and reported (Albert et al., 2015; Bannenberg et al., 2017; Jackowski et al., 2015).

The omega-3 fatty acid dosage needed to elicit beneficial effects on depression may depend on baseline levels. One may speculate that individuals with low omega- 3 fatty acid status are more responsive to supplementation (Carney et al., 2016; Messamore and McNamara, 2016), while a threshold may exist, above which omega-3 fatty acids show no effect. However, one study has found that high blood baseline levels of EPA and DHA in people with depression predict favorable outcomes following omega-3 fatty acid supplementation (Carney et al., 2016). Higher baseline omega-3 blood concentrations may assist in reaching the necessary therapeutic level within the short duration of a clinical trial

A further important issue in research is the choice of outcome measures. Most clinical trials assessing medications in people with depression use rating scales, such as the Hamilton Depression Rating Scale (Hamilton, 1960). However, a statistically significant effect on the scores of such scales does not necessarily indicate an improvement in the symptoms or wellbeing of the individual assessed. Small though statistically significant improvements in scores may not be clinically noticeable by patients or physicians. Doubt has therefore been cast on the clinical significance of differences found between antidepressants and placebo in the available trials (Moncrieff and Kirsch, 2015). A more helpful trial endpoint is the clinical relevance of the effect observed, i.e. whether an intervention produces improvements in patients' daily lives. The minimum difference in rating scale scores indicating a clinically relevant effect remains a matter of debate (Moncrieff and Kirsch, 2015).

An important question to be addressed is whether the efficacy of omega-3 fatty acids depends on a critical age for supplementation. Studies in animals have reported that reduced brain DHA concentrations in the perinatal phase of development are associated with deficits in neuronal arborization, synaptic pathology, cognitive impairment and elevated anxiety and depression-related behaviors (McNamara and Carlson, 2006). In a rat model of chronic deficiency in omega-3 fatty acids, an equilibrated diet administered through the mother during pre- and post-natal periods could restore the offspring's monoaminergic functions, which had been impaired by the deficiency, only if it was provided before the 21st day of life (Kodas et al., 2002; Kodas et al., 2004). These results suggest that an optimal time frame for omega- 3 fatty acid 
Table 1. Overview of findings and problems regarding omega-3 fatty acids and depression

Observational studies

Intake of fish or omega-3 fatty acids was inversely associated with the risk of depression (Hibbeln, 1998)

Fish consumption was associated with a decrease in the risk of depression (Grosso et al., 2016)

Intake of omega-3 fatty acids was negatively associated with depression (Silvers and Scott, 2002; Tanskanen et al., 2001)

Omega-3 fatty acid levels in erythrocytes in people with depression were low compared to controls (Edwards et al., 1998b; Peet et al., 1998)

No associations between the intake of omega-3 fatty acids and depression were found in cross-sectional studies (Appleton et al., 2007; Hakkarainen et al., 2004; Miyake et al., 2006)

No significant relationships between blood omega-3 fatty acid concentrations and depressive symptoms were found in cross-sectional studies (Appleton et al., 2008; Browne et al., 2006; Mamalakis et al., 2004)

Summary: Observational evidence suggesting a link between omega-3 fatty acids and depression may be subject to confounding and cannot establish causal relationships

Randomized controlled intervention studies

Omega-3 fatty acids showed beneficial effects in major depressive disorder (Nemets et al., 2002; Su et al., 2003) and other depressive conditions (Frangou et al., 2006; Stoll et al., 1999)

In other studies, omega-3 fatty acids showed no benefits in major depressive disorder (Grenyer et al., 2007; Silvers et al., 2005) or other depressive disorders (Keck et al., 2006; Rogers et al., 2008)

Beneficial effects of omega-3 fatty acids depended on the severity of depressive symptoms at baseline (benefits with severe depressive symptoms, no benefits with mild depressive symptoms) (Appleton et al., 2010)

The findings of meta-analyses of randomized controlled trials of omega-3 fatty acids for depressive disorders were inconclusive; the benefits of omega-3 fatty acids for depressive symptoms were small to moderate and of little or no clinical relevance (Appleton et al., 2010, 2016; Bloch and Hannestad, 2012; Lin and Su, 2007)

Summary: The effects of omega-3 fatty acid supplementation in depression were usually small or insignificant, with significant heterogeneity between studies

Problems

Available omega-3 fatty acid supplementation trials varied markedly in regard to participants, diagnostic criteria, severity of depression, intervention type, dosage, duration, baseline omega-3 status and outcome measures

EPA rather than DHA appears to mediate the beneficial effects of omega-3 fatty acids in major depressive disorders (Grosso et al., 2014; Hallahan et al., 2016; Martins, 2009; Martins et al., 2012)

Omega-3 fatty acid doses needed to elicit beneficial effects may depend on baseline levels (Carney et al., 2016; Messamore and McNamara, 2016)

The clinical significance of differences between antidepressants and placebo based on rating scales is in doubt (Moncrieff and Kirsch, 2015)

The long-term effects of omega-3 fatty acid supplementation are unclear

Opportunity cost of potentially ineffective therapies needs to be considered; other possibly more useful therapeutic approaches should be investigated (Lange, 2018)

Omega-3 fatty acid supplements may contain potentially toxic oxidation products; potential long-term adverse effects of vitamin E added as antioxidant should be considered (Lange et al., 2019)

Summary: Conclusive evidence of the efficacy of omega-3 fatty acids in depressive disorders is currently lacking

supplementation exists during brain development. Thus, omega-3 fatty acid supplementation in later phases of life may be unable to compensate for deficiencies in critical stages of early brain development.

Further studies with more homogeneous and larger samples are needed. In particular, large-scale studies with sufficiently large numbers of participants with different ranges of omega- 3 fatty acid levels at baseline should be conducted. In future investigations, standardization of inclusion criteria, diagnostic methods, participants' nutritional baseline status, omega-3 fatty acid composition of fish oils and clinically meaningful outcome measures is required. The dose response for both EPA and DHA needs to be examined. Extended follow-up is needed to establish sustained long-term effects of omega-3 fatty acid supplementation in people with depression.

Opportunity cost, i.e. the loss of potential benefits when one alternative is chosen over another, is a relevant issue when recommending potentially ineffective therapies to patients. The administration of omega- 3 fatty acids in addition to evidence-based treatments in people with depression may affect compliance. Furthermore, omega- 3 fatty acids may be taken by patients as a substitute for lifestyle modifications that may be beneficial to their 
mental and physical wellbeing and health (Lange, 2018). Limited research resources may be better used in the development of novel approaches to mental health than in investigating optimal combinations of omega-3 fatty acids, which may offer little benefit in mental disorders.

\section{Conclusion}

Conclusive evidence of the efficacy of omega-3 fatty acids in depressive disorders is currently lacking. Epidemiological studies have found correlative associations between the consumption of fish, the intake of omega- 3 fatty acids and the prevalence of major depressive disorder. Furthermore, lower omega-3 fatty acid levels have been found in people diagnosed with depressive disorders in comparison with controls. However, these observational findings are unable to establish a causal relationship between omega-3 fatty acids and depression. The results of randomized controlled trials of omega-3 fatty acids for depressive disorders are inconclusive, and, to date, these interventional studies have been unable to establish causation between depression and omega-3 fatty acids. Numerous factors may have influenced the results of studies on omega- 3 fatty acid supplementation in the treatment of depression. These factors include heterogeneous types of study design, duration of trials, dosage and types of omega-3 fatty acids used and assessment of outcomes. In light of the results of the available trials in depression, omega-3 fatty acids appear to have little or no therapeutic efficacy.

Issues that should be addressed in more detail include baseline values of omega- 3 fatty acids and symptom severity, the quantity (dosage) and quality (EPA-to-DHA ratio) of the fatty acids used, the duration of supplementation, the concomitant use of medication and long-term efficacy. Very large, well-controlled randomized clinical trials appear to be necessary to establish potential anti-depressive effects of omega-3 fatty acids. However, the substantial expenditure required to conduct such trials is difficult to justify in view of the less than promising findings from available randomized controlled trials.

Potential adverse effects of omega-3 fatty acid administration should be considered. Increased cancer risks may be associated with high-dose omega-3 administration over extended periods of time, possibly due to the effects of omega- 3 fatty acids, their oxidation products or added vitamin E. These effects may become apparent many years after supplementation and their cause may therefore fail to be recognized.

In summary, the efficacy of omega-3 fatty acids in the treatment of depression has not been conclusively demonstrated. The recommendation of potentially ineffective therapies to patients may have considerable opportunity costs, with other possibly more useful therapeutic approaches failing to be utilized.

\section{References}

Adams, P.B., Lawson, S., Sanigorski, A., and Sinclair, A.J. (1996). Arachidonic acid to eicosapentaenoic acid ratio in blood correlates positively with clinical symptoms of depression. Lipids 31(Suppl): S157-S161.

Albert, B.B., Derraik, J.G.B., Cameron-Smith, D., Hofman, P.L., Tumanov, S Villas-Boas, S.G., Garg, M.L., and Cutfield, W.S. (2015). Fish oil supplements in New Zealand are highly oxidised and do not meet label content of n-3 PUFA. Sci. Rep. 5: 7928.

Appleton, K.M., Hayward, R.C., Gunnell, D., Peters, T.J., Rogers, P.J., Kessler, D., and Ness, A.R. (2006). Effects of n-3 long-chain polyunsaturated fatty acids on depressed mood: systematic review of published trials. Am. J. Clin. Nutr. 84(6): 1308-1316.

Appleton, K.M., Peters, T.J., Hayward, R.C., Heatherley, S.V., McNaughton, S.A., Rogers, P.J., Gunnell, D., Ness, A.R., and Kessler, D. (2007). Depressed mood and n-3 polyunsaturated fatty acid intake from fish: non-linear or confounded association? Soc. Psychiatry Psychiatr. Epidemiol. 42(2): 100-104.

Appleton, K.M., Rogers, P.J., and Ness, A.R. (2008). Is there a role for $n-3$ long-chain polyunsaturated fatty acids in the regulation of mood and behaviour? A review of the evidence to date from epidemiological studies, clinical studies and intervention trials. Nutr. Res. Rev. 21(1): 13-41.

Appleton, K.M., Rogers, P.J., and Ness, A.R. (2010). Updated systematic review and meta-analysis of the effects of $n-3$ long-chain polyunsaturated fatty acids on depressed mood. Am. J. Clin. Nutr. 91(3): 757-770.

Appleton, K.M., Sallis, H.M., Perry, R., Ness, A.R., and Churchill, R. (2016). $\omega$-3 Fatty acids for major depressive disorder in adults: an abridged Cochrane review. BMJ Open 6(3): e010172.

Bae, J.-H., and Kim, G. (2018). Systematic review and meta-analysis of omega-3-fatty acids in elderly patients with depression. Nutr. Res. 50: 1-9.

Bai, Z.-G., Bo, A., Wu, S.-J., Gai, Q.-Y., and Chi, I. (2018). Omega-3 polyunsaturated fatty acids and reduction of depressive symptoms in older adults: A systematic review and meta-analysis. J. Affect. Disord. 241: 241-248.

Bannenberg, G., Mallon, C., Edwards, H., Yeadon, D., Yan, K., Johnson, H., and Ismail, A. (2017). Omega-3 Long-Chain Polyunsaturated Fatty Acid Content and Oxidation State of Fish Oil Supplements in New Zealand. Sci Rep. 7(1): 1488.

Barberger-Gateau, P., Jutand, M.A., Letenneur, L., Larrieu, S., Tavernier, B., and Berr, C. (2005). Correlates of regular fish consumption in French elderly community dwellers: data from the Three-City study. Eur. J. Clin. Nutr. 59(7): 817-825.

Bazinet, R.P., and Layé, S. (2014). Polyunsaturated fatty acids and their metabolites in brain function and disease. Nat. Rev. Neurosci. 15(12): 771-785.

Bennett, B.J., Hall, K.D., Hu, F.B., McCartney, A.L., and Roberto, C. (2015). Nutrition and the science of disease prevention: a systems approach to support metabolic health. Ann. N. Y. Acad. Sci. 1352: 1-12.

Bloch, M.H., and Hannestad, J. (2012). Omega-3 fatty acids for the treatment of depression: systematic review and meta-analysis. Mol. Psychiatry 17(12): 1272-1282.

Bondi, C.O., Taha, A.Y., Tock, J.L., Totah, N.K.B, Cheon, Y, Torres, G.E., Rapoport, S.I., and Moghaddam, B. (2014). Adolescent behavior and dopamine availability are uniquely sensitive to dietary omega-3 fatty acid deficiency. Biol. Psychiatry 75(1): 38-46.

Brasky, T.M., Darke, A.K., Song, X., Tangen, C.M., Goodman, P.J., Thompson, I.M., Meyskens, F.L., Goodman, G.E., Minasian, L.M., Parnes, H.L., Klein, E.A., and Kristal, A.R. (2013). Plasma phospholipid fatty acids and prostate cancer risk in the SELECT trial. J. Natl. Cancer Inst. 105(15): 1132-1141.

Brasky, T.M., Till, C., White, E., Neuhouser, M.L., Song, X., Goodman, P., Thompson, I.M., King, I.B., Albanes, D., and Kristal, A.R. (2011). Serum phospholipid fatty acids and prostate cancer risk: results from the prostate cancer prevention trial. Am. J. Epidemiol. 173(12): 14291439.

Browne, J.C., Scott, K.M., and Silvers, K.M. (2006). Fish consumption in pregnancy and omega-3 status after birth are not associated with postnatal depression. J. Affect. Disord. 90(2-3): 131-139.

Bschor, T., and Baethge, C. (2010). No evidence for switching the antidepressant: systematic review and meta-analysis of RCTs of a common therapeutic strategy. Acta Psychiatr. Scand. 121(3): 174-179.

Carlezon, W.A., Mague, S.D., Parow, A.M., Stoll, A.L., Cohen, B.M., and Renshaw, P.F. (2005). Antidepressant-like effects of uridine and omega-3 fatty acids are potentiated by combined treatment in rats. Biol. Psychiatry 57(4): 343-350.

Carney, R.M., Steinmeyer, B.C., Freedland, K.E., Rubin, E.H., Rich, M.W., and Harris, W.S. (2016). Baseline blood levels of omega-3 and depression remission: a secondary analysis of data from a placebo-controlled trial of omega-3 supplements. J. Clin. Psychiatry 77(2): e138-e143.

Carpentier, Y.A., Portois, L., and Malaisse, W.J. (2006). n-3 fatty acids and the metabolic syndrome. Am. J. Clin. Nutr. 83(6 Suppl): 1499S-1504S.

Casacalenda, N., Perry, J.C., and Looper, K. (2002). Remission in major de- 
pressive disorder: a comparison of pharmacotherapy, psychotherapy, and control conditions. Am. J. Psychiatry 159(8): 1354-1360.

Clarke, J., Herzberg, G., Peeling, J., Buist, R., and Corbett, D. (2005). Dietary supplementation of omega-3 polyunsaturated fatty acids worsens forelimb motor function after intracerebral hemorrhage in rats. Exp. Neurol. 191(1): 119-127.

Clarke, J.T., Cullen-Dean, G., Regelink, E., Chan, L., and Rose, V. (1990). Increased incidence of epistaxis in adolescents with familial hypercholesterolemia treated with fish oil. J. Pediatr. 116(1): 139-141.

Crowe, F.L., Appleby, P.N., Travis, R.C., Barnett, M., Brasky, T.M., Bueno-deMesquita, H.B., Chajes, V., Chavarro, J.E., Chirlaque, M.-D., English, D.R., Gibson, R.A., Giles, G.G., Goodman, G.E., Henning, S.M., Kaaks, R., King, I.B., Kolonel, L.N., Kristal, A.R., Neuhouser, M.L., Park, S.-Y., Severi, G., Siddiq, A., Stampfer, M.J., Stattin, P., Tangen, C.M., Tjønneland, A., Trichopoulos, D., Tumino, R., Wilkens, L.R., Key, T.J., and Allen, N.E. (2014). Circulating fatty acids and prostate cancer risk: individual participant meta-analysis of prospective studies. J. Natl. Cancer Inst. 106(9): dju240

Cuijpers, P., Dekker, J., Hollon, S.D., and Andersson, G. (2009). Adding psychotherapy to pharmacotherapy in the treatment of depressive disorders in adults: a meta-analysis. J. Clin. Psychiatry 70(9): 1219-1229.

Cuijpers, P. van Straten, A, van Oppen, P, and Andersson, G. (2008). Are psychological and pharmacologic interventions equally effective in the treatment of adult depressive disorders? A meta-analysis of comparative studies. J. Clin. Psychiatry 69(11): 1675-85.

Deacon, G., Kettle, C., Hayes, D., Dennis, C., and Tucci, J. (2017). Omega 3 polyunsaturated fatty acids and the treatment of depression. Crit. Rev. Food Sci. Nutr. 57(1): 212-223.

DeMar, J.C., Ma, K., Bell, J.M., Igarashi, M., Greenstein, D., and Rapoport, S.I. (2006). One generation of n-3 polyunsaturated fatty acid deprivation increases depression and aggression test scores in rats. J. Lipid. Res. 47(1): 172-180.

Dunn, B.K., Richmond, E.S., Minasian, L.M., Ryan, A.M., and Ford, L.G. (2010). A nutrient approach to prostate cancer prevention: The Selenium and Vitamin E Cancer Prevention Trial (SELECT). Nutr. Cancer 62(7): 896-918.

Edwards, R., Peet, M., Shay, J., and Horrobin, D. (1998a). Depletion of docosahexaenoic acid in red blood cell membranes of depressive patients. Biochem. Soc. Trans. 26(2): S142.

Edwards, R., Peet, M., Shay, J., and Horrobin, D. (1998b). Omega-3 polyunsaturated fatty acid levels in the diet and in red blood cell membranes of depressed patients. J. Affect. Disord. 48(2-3): 149-155.

EFSA Panel on Biological Hazards (BIOHAZ). (2010). Scientific Opinion on Fish Oil for Human Consumption. Food Hygiene, including Rancidity. EFSA Journal 8(10): 1874

Emsley, R., Myburgh, C., Oosthuizen, P., and van Rensburg, S.J. (2002). Randomized, placebo-controlled study of ethyl-eicosapentaenoic acid as supplemental treatment in schizophrenia. Am. J. Psychiatry 159(9): 1596-1598.

Emsley, R., Niehaus, D.J.H., Koen, L., Oosthuizen, P.P., Turner, H.J., Carey, P., van Rensburg, S.J., Maritz, J.S., and Murck, H. (2006). The effects of eicosapentaenoic acid in tardive dyskinesia: a randomized, placebocontrolled trial. Schizophr. Res. 84(1): 112-120.

Esterbauer, H. (1993). Cytotoxicity and genotoxicity of lipid-oxidation products. Am. J. Clin. Nutr. 57(5 Suppl): 779S-785S.

Fantoni, C.M., Cuccio, A.P., and Barrera-Arellano, D. (1996). Brazilian encapsulated fish oils: Oxidative stability and fatty acid composition. J. Am. Oil Chem. Soc. 73(2): 251-253.

Fava, M. (2003). Diagnosis and definition of treatment-resistant depression. Biol. Psychiatry 53(8): 649-659.

Fierens, C., and Corthout, J. (2007). Préparations d'acides gras omega-3: une étude comparative. J. Pharm. Belg. 62(4): 115-119.

Frangou, S., Lewis, M., and McCrone, P. (2006). Efficacy of ethyl-eicosapentaenoic acid in bipolar depression: randomised double-blind placebocontrolled study. Br. J. Psychiatry 188: 46-50.

Fristad, M.A., Vesco, A.T., Young, A.S., Healy, K.Z., Nader, E.S., Gardner, W., Seidenfeld, A.M., Wolfson, H.L., and Arnold, L.E. (2019). Pilot Randomized Controlled Trial of Omega-3 and Individual-Family Psychoeducational Psychotherapy for Children and Adolescents With Depression. J. Clin. Child Adolesc. Psychol. (Suppl. 1): S105-S118.

Gabbay, V., Freed, R.D., Alonso, C.M., Senger, S., Stadterman, J., Davison,
B.A., and Klein, R.G. (2018). A Double-Blind Placebo-Controlled Trial of Omega-3 Fatty Acids as a Monotherapy for Adolescent Depression. J. Clin. Psychiatry 79(4): $17 \mathrm{~m} 11596$.

Golding J, Steer, C., Emmett, P., Davis, J.M., and Hibbeln, J.R. (2009). High levels of depressive symptoms in pregnancy with low omega-3 fatty acid intake from fish. Epidemiology 20(4): 598-603.

Grenyer, B.F.S., Crowe, T., Meyer, B., Owen, A.J., Grigonis-Deane, E.M., Caputi, P., and Howe, P.R.C. (2007). Fish oil supplementation in the treatment of major depression: a randomised double-blind placebocontrolled trial. Prog. Neuropsychopharmacol. Biol. Psychiatry 31(7): 1393-1396.

Grosso, G., Micek, A., Marventano, S., Castellano, S., Mistretta, A., Pajak, A., and Galvano, F. (2016). Dietary n-3 PUFA, fish consumption and depression: A systematic review and meta-analysis of observational studies. J. Affect. Disord. 205: 269-281.

Grosso, G., Pajak, A., Marventano, S., Castellano, S., Galvano, F., Bucolo, C., Drago, F., and Caraci, F. (2014). Role of omega-3 fatty acids in the treatment of depressive disorders: a comprehensive meta-analysis of randomized clinical trials. PLoS One 9(5): e96905.

Hakkarainen, R., Partonen, T., Haukka, J., Virtamo, J., Albanes, D., and Lönnqvist, J. (2004). Is low dietary intake of omega-3 fatty acids associated with depression? Am. J. Psychiatry 161(3): 567-569.

Hall, K.T., Buring, J.E., Mukamal, K.J., Vinayaga Moorthy, M., Wayne, P.M., Kaptchuk, T.J., Battinelli, E.M., Ridker, P.M., Sesso, H.D., Weinstein, S.J., Albanes, D., Cook, N.R., and Chasman, D.I. (2019). COMT and Alpha-Tocopherol Effects in Cancer Prevention: Gene-Supplement Interactions in Two Randomized Clinical Trials. J. Natl. Cancer Inst. 111(7): 684-694.

Hallahan, B., Ryan, T., Hibbeln, J.R., Murray, I.T., Glynn, S., Ramsden, C.E., SanGiovanni, J.P., and Davis, J.M. (2016). Efficacy of omega-3 highly unsaturated fatty acids in the treatment of depression. Br. J. Psychiatry 209(3): 192-201.

Halvorsen, B.L., and Blomhoff, R. (2011). Determination of lipid oxidation products in vegetable oils and marine omega- 3 supplements. Food Nutr. Res. 55: 5792

Hamilton, M. (1960). A rating scale for depression. J. Neurol. Neurosurg. Psychiatry 23: 56-62.

Hanson, S., Thorpe, G., Winstanley, L., Abdelhamid, A.S., and Hooper, L. (2020). Omega-3, omega- 6 and total dietary polyunsaturated fat on cancer incidence: systematic review and meta-analysis of randomised trials. Br. J. Cancer 122: 1260-1270.

Hauser, J., Stollberg, E., Reissmann, A., Kaunzinger, I., and Lange, K.W. (2018). Effects of omega-3 fatty acids and sugar on attention in the spontaneously hypertensive rat. J. Funct. Foods 48: 676-681.

Hibbeln, J.R. (1998). Fish consumption and major depression. Lancet 351(9110): 1213

Hsu, M.-C., Tung, C.-Y, and Chen, H.-E. (2018). Omega-3 polyunsaturated fatty acid supplementation in prevention and treatment of maternal depression: Putative mechanism and recommendation. J. Affect. Disord. 238: 47-61.

Huang, S.-Y., Yang, H.-T., Chiu, C.-C., Pariante, C.M., and Su, K.-P. (2008). Omega-3 fatty acids on the forced-swimming test. J. Psychiatr. Res. 42(1): 58-63.

Insel, T.R. (2015). The NIMH experimental medicine initiative. World Psychiatry 14(2): 151-153.

Jackowski, S.A., Alvi, A.Z., Mirajkar, A., Imani, Z., Gamalevych, Y., Shaikh, N.A., and Jackowski, G. (2015). Oxidation levels of North American over-the-counter n-3 (omega-3) supplements and the influence of supplement formulation and delivery form on evaluating oxidative safety. J. Nutr. Sci. 4: e30.

Jans, L.A.W., Riedel, W.J., Markus, C.R., and Blokland, A. (2007). Serotonergic vulnerability and depression: assumptions, experimental evidence and implications. Mol. Psychiatry 12(6): 522-543.

Jazayeri, S., Tehrani-Doost, M., Keshavarz, S.A., Hosseini, M., Djazayery, A., Amini, H., Jalali, M., and Peet, M. (2008). Comparison of therapeutic effects of omega-3 fatty acid eicosapentaenoic acid and fluoxetine, separately and in combination, in major depressive disorder. Aust. N. Z. J. Psychiatry 42(3): 192-198.

Jensen, T.K., Priskorn, L., Holmboe, S.A., Nassan, F.L., Andersson, A.-M., Dalgård, C., Petersen, J.H., Chavarro, J.E., and Jørgensen, N. (2020). Associations of fish oil supplement use with testicular function in young men. JAMA Netw. Open 3(1): e1919462. 
Kaneda, T., and Ishii, S. (1953). Studies on the nutritive value of lipids. VIII. Nutritive value or toxicity of highly unsaturated fatty acids. Bull. Jap. Soc. Sci. Fisheries 19: 171-177.

Keck, P.E., Mintz, J., McElroy, S.L., Freeman, M.P., Suppes, T., Frye, M.A., Altshuler, L.L., Kupka, R., Nolen, W.A., Leverich, G.S., Denicoff, K.D. Grunze, H., Duan, N., and Post, R.M. (2006). Double-blind, randomized, placebo-controlled trials of ethyl-eicosapentanoate in the treatment of bipolar depression and rapid cycling bipolar disorder. Biol. Psychiatry 60(9): 1020-1022.

Kessler, R.C., Angermeyer, M., Anthony, J.C., Graaf, R.d.e., Demyttenaere, K., Gasquet, I., Girolamo, G.d.e., Gluzman, S., Gureje, O., Haro, J.M., Kawakami, N., Karam, A., Levinson, D., Medina Mora, M.E., Oakley Browne, M.A., Posada-Villa, J., Stein, D.J., Adley Tsang, C.H., AguilarGaxiola, S., Alonso, J., Lee, S., Heeringa, S., Pennell, B.-E., Berglund, P., Gruber, M.J., Petukhova, M., Chatterji, S., and Ustün, T.B. (2007). Lifetime prevalence and age-of-onset distributions of mental disorders in the World Health Organization's World Mental Health Survey Initiative. World Psychiatry 6(3): 168-176.

Kessler, R.C., Berglund, P., Demler, O., Jin, R., Koretz, D., Merikangas, K.R. Rush, A.J., Walters, E.E., and Wang, P.S. (2003). The epidemiology of major depressive disorder: results from the National Comorbidity Survey Replication (NCS-R). JAMA 289(23): 3095-3105.

Klein, E.A., Thompson, I.M., Tangen, C.M., Crowley, J.J., Lucia, M.S., Goodman, P.J., Minasian, L.M., Ford, L.G., Parnes, H.L., Gaziano, J.M., Karp D.D., Lieber, M.M., Walther, P.J., Klotz, L., Parsons, J.K., Chin, J.L., Darke, A.K., Lippman, S.M., Goodman, G.E., Meyskens, F.L., and Baker, L.H. (2011). Vitamin E and the risk of prostate cancer: the Selenium and Vitamin E Cancer Prevention Trial (SELECT). JAMA 306(14): 1549-1556.

Kodas, E., Galineau, L., Bodard, S., Vancassel, S., Guilloteau, D., Besnard, J.-C., and Chalon, S. (2004). Serotoninergic neurotransmission is affected by $n-3$ polyunsaturated fatty acids in the rat. J. Neurochem. 89(3): 695-702.

Kodas, E., Vancassel, S., Lejeune, B., Guilloteau, D., and Chalon, S. (2002). Reversibility of $n-3$ fatty acid deficiency-induced changes in dopaminergic neurotransmission in rats: critical role of developmental stage. J. Lipid. Res. 43(8): 1209-1219.

Kolanowski, W. (2010). Omega-3 LC PUFA contents and oxidative stability of encapsulated fish oil dietary supplements. Int. J. Food Prop. 13(3): 498-511.

Krishnan, V., and Nestler, E.J. (2008). The molecular neurobiology of depression. Nature 455(7215): 894-902.

Lafourcade, M., Larrieu, T., Mato, S., Duffaud, A., Sepers, M., Matias, I., De Smedt-Peyrusse, V., Labrousse, V.F., Bretillon, L., Matute, C., Rodríguez-Puertas, R., Layé, S., and Manzoni, O.J. (2011). Nutritional omega-3 deficiency abolishes endocannabinoid-mediated neuronal functions. Nat. Neurosci. 14(3): 345-350.

Lai, J.S., Hiles, S., Bisquera, A., Hure, A.J., McEvoy, M., and Attia, J. (2014). A systematic review and meta-analysis of dietary patterns and depression in community-dwelling adults. Am. J. Clin. Nutr. 99(1): 181-197.

Lakhwani, L., Tongia, S.K., Pal, V.S., Agrawal, R.P., Nyati, P., and Phadnis, P. (2007). Omega-3 fatty acids have antidepressant activity in forced swimming test in Wistar rats. Acta Pol. Pharm. 64(3): 271-276.

Lange, K.W. (2018). Diet, exercise, and mental disorders - public health challenges of the future. Mov. Nutr. Health Dis. 2: 39-59.

Lange, K.W. (2020a). Lipids in the treatment of mental disorders. In: Shahidi, F. (Ed.). Bailey's Industrial Oil and Fat Products. Wiley, pp. 371-390.

Lange, K.W. (2020b). Lipids in the treatment of neurodegenerative diseases. In: Shahidi, F. (Ed.). Bailey's Industrial Oil and Fat Products. Wiley, pp. 347-363.

Lange, K.W. (2020c). Omega-3 fatty acids and mental health. Glob. Health J. 4(1): 18-30

Lange, K.W., Nakamura, Y., and Lange, K.M. (2020). The use of probiotics in depression. J. Food Bioact. 12: 3-8.

Lange, K.W., Nakamura, Y., Gosslau, A.M., and Li, S. (2019). Are there serious adverse effects of omega- 3 polyunsaturated fatty acid supplements? J. Food Bioact. 7: 1-6.

Lange, K.W., Nakamura, Y., Lange, K.M., and Zhao, H. (2021). Tea and depression. Food Sci. Hum. Wellness 10.

Lange, K.W., Stollberg, E., Nakamura, Y., and Hauser, J. (2018). Behaviora assessment of hippocampal function following dietary intervention. Food Sci. Hum. Wellness 7(3): 229-233.
Larrieu, T., and Layé, S. (2018). Food for mood: relevance of nutritional omega-3 fatty acids for depression and anxiety. Front. Physiol. 9: 1047.

Larrieu, T., Hilal, M.L., Hilal, L.M., Fourrier, C., De Smedt-Peyrusse, V., Sans, N., N, S., Capuron, L., and Layé, S. (2014). Nutritional omega-3 modulates neuronal morphology in the prefrontal cortex along with depression-related behaviour through corticosterone secretion. Transl. Psychiatry 4: e437.

Larrieu, T, Hilal, M.L, De Smedt-Peyrusse, V., Sans, N., and Layé, S. (2016) Nutritional omega-3 deficiency alters glucocorticoid receptor-signaling pathway and neuronal morphology in regionally distinct brain structures associated with emotional deficits. Neural. Plast. 2016: 8574830 .

Liao, Y., Xie, B., Zhang, H., He, Q., Guo, L., Subramaniapillai, M., Fan, B., Lu, C., and Mclntyer, R.S. (2019). Efficacy of omega-3 PUFAs in depression: A meta-analysis. Transl. Psychiatry 9(1): 190.

Lim, S.Y, Kim, E.J., Kim, A., Lee, H.J., Choi, H.J., and Yang, S.J. (2016). Nutritional factors affecting mental health. Clin. Nutr. Res. 5(3): 143-152.

Lin, P.-Y., and Su, K.-P. (2007). A meta-analytic review of double-blind, placebo-controlled trials of antidepressant efficacy of omega-3 fatty acids. J. Clin. Psychiatry 68(7): 1056-1061.

Malhi, G.S., and Mann, J.J. (2018). Depression. Lancet 392(10161): 22992312.

Mamalakis, G., Kiriakakis, M., Tsibinos, G., and Kafatos, A. (2004). Depression and adipose polyunsaturated fatty acids in an adolescent group. Prostaglandins Leukot. Essent. Fatty Acids 71(5): 289-294.

Mann, R., Gilbody, S., and Adamson, J. (2010). Prevalence and incidence of postnatal depression: what can systematic reviews tell us? Arch. Womens Ment. Health 13(4): 295-305.

Martins, J.G. (2009). EPA but not DHA appears to be responsible for the efficacy of omega-3 long chain polyunsaturated fatty acid supplementation in depression: evidence from a meta-analysis of randomized controlled trials. J. Am. Coll. Nutr. 28(5): 525-542.

Martins, J.G., Bentsen, H., and Puri, B.K. (2012). Eicosapentaenoic acid appears to be the key omega- 3 fatty acid component associated with efficacy in major depressive disorder: a critique of Bloch and Hannestad and updated meta-analysis. Mol. Psychiatry 17(12): 1144-9.

Marx, W., Moseley, G., Berk, M., and Jacka, F. (2017). Nutritional psychiatry: the present state of the evidence. Proc. Nutr. Soc. 76(4): 427-436.

Matsuo, N. (1954). Studies on the toxicity of fish oil. J. Biochem. 41(4): 481-487.

McEwen, B.J., Morel-Kopp, M.-C., Chen, W., Tofler, G.H., and Ward, C.M. (2013). Effects of omega-3 polyunsaturated fatty acids on platelet function in healthy subjects and subjects with cardiovascular disease. Semin. Thromb. Hemost. 39(1): 25-32.

McNamara, R.K., and Carlson, S.E. (2006). Role of omega-3 fatty acids in brain development and function: potential implications for the pathogenesis and prevention of psychopathology. Prostaglandins Leukot. Essent. Fatty Acids 75(4-5): 329-349.

McNamara, R.K., and Liu, Y. (2011). Reduced expression of fatty acid biosynthesis genes in the prefrontal cortex of patients with major depressive disorder. J. Affect. Disord. 129(1-3): 359-363.

Mehta, D. (2004). British National Formulary Number 47 March 2004. British Medical Association, London.

Messamore, E., and McNamara, R.K. (2016). Detection and treatment of omega-3 fatty acid deficiency in psychiatric practice: Rationale and implementation. Lipids Health Dis. 15: 25.

Miller, G. (2010). Is pharma running out of brainy ideas? Science 329(5991): 502-504.

Miyake, Y., Sasaki, S., Yokoyama, T., Tanaka, K., Ohya, Y., Fukushima, W., Saito, K., Ohfuji, S., Kiyohara, C., and Hirota, Y. (2006). Risk of postpartum depression in relation to dietary fish and fat intake in Japan: the Osaka Maternal and Child Health Study. Psychol. Med. 36(12): 1727-1735.

Moncrieff, J., and Kirsch, I. (2015). Empirically derived criteria cast doubt on the clinical significance of antidepressant-placebo differences. Contemp. Clin. Trials 43: 60-62.

Müller, C.P., Reichel, M., Mühle, C., Rhein, C., Gulbins, E., and Kornhuber, J. (2015). Brain membrane lipids in major depression and anxiety disorders. Biochim. Biophys. Acta 1851(8): 1052-1065.

Nasir, M., and Bloch, M.H. (2019). Trim the fat: the role of omega-3 fatty acids in psychopharmacology. Ther. Adv. Psychopharmacol. 9: 
2045125319869791.

Nemets, B., Stahl, Z., and Belmaker, R.H. (2002). Addition of omega-3 fatty acid to maintenance medication treatment for recurrent unipolar depressive disorder. Am. J. Psychiatry 159(3): 477-479.

Nüesch, E., Trelle, S., Reichenbach, S., Rutjes, A.W.S., Tschannen, B., Altman, D.G., Egger, M., and and Jüni, P. (2010). Small study effects in metaanalyses of osteoarthritis trials: meta-epidemiological study. BMJ 341 c3515.

Opie, R.S., O'Neil, A., Itsiopoulos, C., and Jacka, F.N. (2015). The impact of whole-of-diet interventions on depression and anxiety: a systematic review of randomised controlled trials. Public Health Nutr. 18(11) 2074-2093.

Opperman, M., and Benade, S. (2013). Analysis of the omega-3 fatty acid content of South African fish oil supplements: a follow-up study. Cardiovasc. J. Afr. 24(8): 297-302.

Parletta, N., Zarnowiecki, D., Cho, J., Wilson, A., Procter, N., Gordon, A., Bogomolova, S., O'Dea, K., Strachan, J., Ballestrin, M., Champion, A., and Meyer, B.J. (2016). People with schizophrenia and depression have a low omega-3 index. Prostaglandins Leukot. Essent. Fatty Acids 110: 42-47.

Pascoe, M.C., Howells, D.W., Crewther, D.P., Constantinou, N., Carey, L.M., Rewell, S.S., Turchini, G.M., Kaur, G., and Crewther, S.G. (2014). Fish oil diet associated with acute reperfusion related hemorrhage, and with reduced stroke-related sickness behaviors and motor impairment. Front. Neurol. 5: 14.

Peet, M., Murphy, B., Shay, J., and Horrobin, D. (1998). Depletion of omega-3 fatty acid levels in red blood cell membranes of depressive patients. Biol. Psychiatry 43(5): 315-319.

Planchez, B., Surget, A., and Belzung, C. (2019). Animal models of major depression: drawbacks and challenges. J. Neural Transm. 126(11) 1383-1408.

Psaltopoulou, T., Sergentanis, T.N., Panagiotakos, D.B., Sergentanis, I.N., Kosti, R., and Scarmeas, N. (2013). Mediterranean diet, stroke, cognitive impairment, and depression: A meta-analysis. Ann. Neurol. 74(4): 580-591.

Rees, A.-M., Austin, M.-P., Owen, C., and Parker, G. (2009). Omega-3 deficiency associated with perinatal depression: case control study. Psychiatry Res. 166(2-3): 254-259.

Rogers, P.J., Appleton, K.M., Kessler, D., Peters, T.J., Gunnell, D., Hayward, R.C., Heatherley, S.V., Christian, L.M., McNaughton, S.A., and Ness, A.R. (2008). No effect of $n-3$ long-chain polyunsaturated fatty acid (EPA and DHA) supplementation on depressed mood and cognitive function: a randomised controlled trial. Br. J. Nutr. 99(2): 421-431.

Ross, S.M. (2016). Omega-3 fatty acids: clinical applications in the treatment of depression. Holist. Nurs. Pract. 30(6): 382-385.

Ruhland, S., Hauser, J., Kaunzinger, I., Nakamura, Y., Stollberg, E., and Lange, K.W. (2020). Effects of omega-3 fatty acids on working memory in rats with increased sugar intake. J. Funct. Foods 69: 103951.

Rush, A.J., Trivedi, M.H., Wisniewski, S.R., Nierenberg, A.A., Stewart, J.W., Warden, D., Niederehe, G., Thase, M.E., Lavori, P.W., Lebowitz, B.D. McGrath, P.J., Rosenbaum, J.F., Sackeim, H.A., Kupfer, D.J., Luther, J., and Fava, M. (2006a). Acute and longer-term outcomes in depressed outpatients requiring one or several treatment steps: a STAR*D report. Am. J. Psychiatry 163(11): 1905-1917.

Rush, A.J., Trivedi, M.H., Wisniewski, S.R., Stewart, J.W., Nierenberg, A.A., Thase, M.E., Ritz, L., Biggs, M.M., Warden, D., Luther, J.F., Shores-Wilson, K., Niederehe, G., and Fava, M. (2006b). Bupropion-SR, sertraline, or venlafaxine-XR after failure of SSRIs for depression. N. Engl. J. Med. 354(12): 1231-1242.

Sackett, D.L. (1979). Bias in analytic research. J. Chronic Dis. 32(1-2): 51-63.

Sarris, J., Murphy, J., Mischoulon, D., Papakostas, G.I., Fava, M., Berk, M., and $\mathrm{Ng}, \mathrm{C} . \mathrm{H}$. (2016). Adjunctive nutraceuticals for depression: a systematic review and meta-analyses. Am. J. Psychiatry 173(6): 575-587.

Sastry, P.S. (1985). Lipids of nervous tissue: composition and metabolism. Prog. Lipid Res. 24(2): 69-176.

Silvers, K.M., and Scott, K.M. (2002). Fish consumption and self-reported physical and mental health status. Public Health Nutr. 5(3): 427-431.

Silvers, K.M., Woolley, C.C., Hamilton, F.C., Watts, P.M., and Watson, R.A.
(2005). Randomised double-blind placebo-controlled trial of fish oil in the treatment of depression. Prostaglandins Leukot. Essent. Fatty Acids 72(3): 211-218.

Simpson, W., Steiner, M., Coote, M., and Frey, B.N. (2016). Relationship between inflammatory biomarkers and depressive symptoms during late pregnancy and the early postpartum period: a longitudinal study. Braz. J. Psychiatry 38(3): 190-196.

Song, C., Zhang, X.Y., and Manku, M. (2009). Increased phospholipase A2 activity and inflammatory response but decreased nerve growth factor expression in the olfactory bulbectomized rat model of depression: effects of chronic ethyl-eicosapentaenoate treatment. J. Neurosci. 29(1): 14-22.

Sontrop, J., and Campbell, M.K. (2006). Omega-3 polyunsaturated fatty acids and depression: a review of the evidence and a methodological critique. Prev. Med. 42(1): 4-13.

Sontrop, J., Avison, W.R., Evers, S.E., Speechley, K.N., and Campbell, M.K. (2008). Depressive symptoms during pregnancy in relation to fish consumption and intake of $\mathrm{n}-3$ polyunsaturated fatty acids. Paediatr. Perinat. Epidemiol. 22(4): 389-399.

Sterne, J.A., Gavaghan, D., and Egger, M. (2000). Publication and related bias in meta-analysis: power of statistical tests and prevalence in the literature. J. Clin. Epidemiol. 53(11): 1119-1129.

Stoll, A.L., Severus, W.E., Freeman, M.P., Rueter, S., Zboyan, H.A., Diamond, E., Cress, K.K., and Marangell, L.B. (1999). Omega 3 fatty acids in bipolar disorder: a preliminary double-blind, placebo-controlled trial. Arch. Gen. Psychiatry 56(5): 407-412.

Su, K.-P., Huang, S.-Y., Chiu, C.-C., and Shen, W.W. (2003). Omega-3 fatty acids in major depressive disorder. A preliminary double-blind, placebocontrolled trial. Eur. Neuropsychopharmacol. 13(4): 267-271.

Sublette, M.E., Ellis, S.P., Geant, A.L., and Mann, J.J. (2011). Meta-analysis of the effects of eicosapentaenoic acid (EPA) in clinical trials in depression. J. Clin. Psychiatry 72(12): 1577-1584.

Sudheendran, S., Chang, C.C., and Deckelbaum, R.J. (2010). N-3 vs. saturated fatty acids: effects on the arterial wall. Prostaglandins Leukot. Essent. Fatty Acids 82(4-6): 205-209.

Sydenham, E., Dangour, A.D., and Lim, W.-S. (2012). Omega 3 fatty acid for the prevention of cognitive decline and dementia. Cochrane Database Syst. Rev. (6): CD005379.

Tanskanen, A., Hibbeln, J.R., Hintikka, J., Haatainen, K., Honkalampi, K., and Viinamäki, H. (2001). Fish consumption, depression, and suicidality in a general population. Arch. Gen. Psychiatry 58(5): 512-513.

Taylor, B.S., Schultz, N., Hieronymus, H., Gopalan, A., Xiao, Y., Carver, B.S., Arora, V.K., Kaushik, P., Cerami, E., Reva, B., Antipin, Y., Mitsiades, N., Landers, T., Dolgalev, I., Major, J.E., Wilson, M., Socci, N.D., Lash, A.E., Heguy, A., Eastham, J.A., Scher, H.I., Reuter, V.E., Scardino, P.T., Sander, C., Sawyers, C.L., and Gerald, W.L. (2010). Integrative genomic profiling of human prostate cancer. Cancer Cell. 18(1): 11-22.

Watts, E.L., Appleby, P.N., Perez-Cornago, A., Bueno-de-Mesquita, H.B., Chan, J.M., Chen, C., Cohn, B.A., Cook, M.B., Flicker, L., Freedman, N.D., Giles, G.G., Giovannucci, E., Gislefoss, R.E., Hankey, G.J., Kaaks, R., Knekt, P., Kolonel, L.N., Kubo, T., Le Marchand, L., Luben, R.N., Luostarinen, T., Männistö, S., Metter, E.J., Mikami, K., Milne, R.L., Ozasa, K., Platz, E.A., Quirós, J.R., Rissanen, H., Sawada, N., Stampfer, M., Stanczyk, F.Z., Stattin, P., Tamakoshi, A., Tangen, C.M., Thompson, I.M., Tsilidis, K.K., Tsugane, S., Ursin, G., Vatten, L., Weiss, N.S., Yeap, B.B., Allen, N.E., Key, T.J., and Travis, R.C. (2018). Low free testosterone and prostate cancer risk: a collaborative analysis of 20 prospective studies. Eur. Urol. 74(5): 585-594.

World Health Organization. (2008). The global burden of disease: 2004 update. World Health Organization, Geneva, Switzerland.

Yang, C.S., Suh, N., and Kong, A.-N.T. (2012). Does vitamin E prevent or promote cancer? Cancer Prev. Res. 5(5): 701-705.

Yang, Y., Kim, Y., and Je, Y. (2018). Fish consumption and risk of depression: Epidemiological evidence from prospective studies. Asia Pac. Psychiatry 10(4): e12335.

Zuta, P.C., Simpson, B.K., Zhao, X., and Leclerc, L. (2007). The effect of $\alpha$-tocopherol on the oxidation of mackerel oil. Food Chemistry 100(2): $800-807$. 